Article

\title{
Evaluation of the Bond Strength and Cytotoxicity of Alkasite Restorative Material
}

\author{
Mohamed M. Awad 1,*(D), Turki Alshehri ${ }^{2}$, Ahmed M. Alqarni ${ }^{2}$, Nashaat M. Magdy ${ }^{1}$, \\ Feras Alhalabi ${ }^{1}$, Dalal Alotaibi ${ }^{3}$ and Ali Alrahlah $4,5, *$ iD \\ 1 Department of Conservative Dental Sciences, College of Dentistry, Prince Sattam Bin Abdulaziz University, \\ Al-Kharj 11942, Saudi Arabia; n.emam@psau.edu.sa (N.M.M.); f.alhalabi@psau.edu.sa (F.A.) \\ 2 College of Dentistry, Prince Sattam Bin Abdulaziz University, Al-Kharj 11942, Saudi Arabia; \\ 434050098@std.psau.edu.sa (T.A.); 434050497@std.psau.edu.sa (A.M.A.) \\ 3 Department of Periodontics and Community Dentistry, College of Dentistry, King Saud University, \\ Riyadh 11545, Saudi Arabia; dalalotaibi@ksu.edu.sa \\ 4 Department of Restorative Dental Science, College of Dentistry, King Saud University, \\ Riyadh 11545, Saudi Arabia \\ 5 Engineer Abdullah Bugshan Research Chair for Dental and Oral Rehabilitation, King Saud University, \\ Riyadh 11545, Saudi Arabia \\ * Correspondence: dr.mm.awad@hotmail.com or m.awad@psau.edu.sa (M.M.A.); \\ aalrahlah@ksu.edu.sa (A.A.)
}

Received: 7 August 2020; Accepted: 1 September 2020; Published: 4 September 2020

\begin{abstract}
Cention N (CN; Ivoclar Vivadent, Schaan, Liechtenstein), advertised as an alkasite, is a bioactive bulk-fill resin-based composite (BF-RBC) with alkaline fillers. This study evaluated the resin-dentin micro-tensile bond strength ( $\mu \mathrm{TBS}$ ) and cytotoxicity of $\mathrm{CN}$. Methods: Flat dentin surfaces were obtained, bonded with a universal adhesive, and randomly distributed into two groups. CN (group I) and a flowable BF-RBC, namely, Tetric N-Flow Bulk Fill, Ivoclar Vivadent, Schaan, Liechtenstein (group II), were used. After thermocycling, bonded samples were sectioned into micro-beams for $\mu$ TBS evaluation. Resin-based composite (RBC) discs with a thickness of 2 and $4 \mathrm{~mm}$ were tested on human gingival fibroblast cells (HGFCs). Cytotoxicity was assessed by cell viability and growth using AlamarBlue ${ }^{\circledR}$ (Biosource, Camarillo, CA, USA) over a seven-day period. Independent t-test was utilized to statistically analyze $\mu$ TBS data, while one- and two-way analysis of variance (ANOVA) and Tukey's post-hoc tests were utilized to analyze the cell viability data. Results: There was no statistically significant difference $(p>0.05)$ in the $\mu$ TBS between the flowable BF-RBC and $\mathrm{CN}$. For both materials, the HGFCs were viable, with constant growing over the seven-day period. Conclusion: $\mathrm{CN}$ provided a resin-dentin $\mu$ TBS that was comparable to that provided by the flowable BF-RBC. Both materials showed acceptable cytotoxicity over the seven-day period at a thickness of both 2 and $4 \mathrm{~mm}$.
\end{abstract}

Keywords: alkasite; bulk-fill; resin-based composite; micro-tensile bond strength; dentin; cytotoxicity

\section{Introduction}

Resin-based composite (RBC) materials can be used efficiently to restore large-size posterior cavities [1,2]. Conventional RBC cannot be adequately light-cured in more than $2 \mathrm{~mm}$ increments [3]. Bulk-fill RBC (BF-RBC) materials allow the placement of posterior restorations in thick increments, making the restorative procedure less technique-sensitive [4]. Light-cured BF-RBC materials [5,6] and restorations [7] have been extensively evaluated in-vitro, showing mechanical properties comparable to those of conventional RBCs [8]. Whether BF-RBCs or conventional RBCs are used, the marginal integrity in-vitro is similar in posterior restorations [7,8]. Additionally, clinical studies have 
proven that, over follow-up periods of one to six years, the clinical performance is also similar [9]. Using regular-viscosity BF-RBCs requires shorter placement times in restorations [10]. Compared to conventional RBCs, the primary advantage of BF-RBCs is their higher depth of cure, which allows clinicians to apply them in thicker increments. However, a recent systematic review showed that adequate light-curing at a 4-mm depth might not be achievable with all BF-RBCs [11]. Moreover, to achieve an adequate depth of cure at $4 \mathrm{~mm}$, BF-RBCs should be light-cured at a high irradiance $\left(\geq 1000 \mathrm{~mW} / \mathrm{cm}^{2}\right)$ [5]. Thus, some clinicians doubt whether the depth of cure is sufficient [12]. Inadequate polymerization of RBCs would not only impair their mechanical properties, but could also reduce the degree of conversion and increase the residual monomer content [13], resulting in more adverse cytotoxic effects $[14,15]$. Such cytotoxicity of BF-RBCs can be material dependent [16], and their chemical composition, thickness, and amount of ions released significantly influence their cytotoxicity [6].

Cention N (CN; Ivoclar Vivadent, Schaan, Liechtenstein), advertised as an alkasite (a RBC with alkaline fillers), is a powder/liquid, self-cured BF-RBC, with a light-curing option. This material has an enhanced polymerization system and provides additional bioactive or ion releasing properties [12]. Its mechanical and micromechanical properties and wear behaviors support its use in posterior restorations [12,17]. Compared to conventional RBCs, CN shows greater monomer conversion [18], and it can decrease dentin demineralization as a result of its bioactivity [19].

Effective in-vitro evaluations of new restorative materials, including their biological and mechanical aspects, are required before clinical trials can be conducted [20]. The biological assessment of new dental materials is essential to predict their clinical performance [21]. In addition, bond strength testing could be a helpful tool for evaluating experimental variables [22].

Previous studies have compared the resin-dentin shear bond strength (SBS) and micro-tensile bond strength ( $\mu \mathrm{TBS}$ ) between $\mathrm{CN}$ and a conventional RBC [23] as well as between a self-adhesive $\mathrm{RBC}$ and a resin-modified glass ionomer cement (RMGIC) [24]. CN showed higher immediate SBS than conventional RBC [23] and superior $\mu$ TBS to self-adhesive RBC and resin-modified glass ionomer restorative [24]. However, the bond strength of $\mathrm{CN}$ has not been evaluated in comparison to light-cured BF-RBCs. Moreover, the cytotoxicity of $\mathrm{CN}$ has not yet been evaluated. Both the bond strength and the cytotoxicity of $\mathrm{CN}$ may affect the clinical performance of $\mathrm{CN}$ restorations. Therefore, the aim of this in-vitro study was to assess the resin-dentin $\mu$ TBS and cytotoxicity of $\mathrm{CN}$ in comparison it to those of a light-cured flowable BF-RBC. It was hypothesized that (1) the resin-dentin $\mu$ TBS of CN and of a flowable BF-RBC would not differ significantly, and (2) the cell viability for both materials would not differ significantly at thicknesses of 2 and $4 \mathrm{~mm}$.

\section{Materials and Methods}

This study was conducted in accordance with the Declaration of Helsinki, and the protocol was approved by the Ethics Committee of College of Dentistry, Prince Sattam Bin Abdulaziz University Institutional Review Board (IRB No. PSAU2020019). The materials used in the study and their composition are described in Table 1.

Table 1. Materials used in the study.

\begin{tabular}{|c|c|}
\hline Material and Manufacturer & Composition \\
\hline $\begin{array}{l}\text { Cention N, Ivoclar Vivadent, Schaan, } \\
\text { Liechtenstein. }\end{array}$ & $\begin{array}{l}\text { UDMA, tricyclodecan-dimethanol dimethacrtylate, polyethylene glycol } \\
\text { dimethacrylate, inorganic fillers and customized fillers }\end{array}$ \\
\hline $\begin{array}{l}\text { Tetric N-Flow Bulk Fill, Ivoclar Vivadent, } \\
\text { Schaan, Liechtenstein }\end{array}$ & $\begin{array}{l}\text { Bis-GMA, UDMA, TEGDMA, Ivocerin, Barium glass, ytterbium } \\
\text { trifluoride, mixed oxide, silicon dioxide }\end{array}$ \\
\hline $\begin{array}{l}\text { Tetric N-Bond Universal, Ivoclar Vivadent, } \\
\text { Schaan, Liechtenstein }\end{array}$ & $\begin{array}{c}\text { MDP, MCAP, HEMA, D3MA water, ethanol, silicon dioxide, initiators, } \\
\text { and stabilizers }\end{array}$ \\
\hline
\end{tabular}




\section{1. $\mu$ TBS}

Ten permanent molars were obtained and stored in chloramine-T solution $(0.5 \%)$ for 14 days, and then in distilled water at $4{ }^{\circ} \mathrm{C}$ until used (all were used within 90 days of extraction). Each was embedded in self-curing acrylic resin $2 \mathrm{~mm}$ below the cemento-enamel junction. Using a diamond saw at low speed and under running water, the occlusal surfaces were cut flat horizontally to obtain the mid-coronal dentin. The cut occlusal surfaces were then polished with a 600-grit sand disc for $15 \mathrm{~s}$ to obtain a smear layer, and then ultrasonic cleaning was performed for $5 \mathrm{~min}$ to remove debris. The exposed dentin surfaces were etched with $37 \%$ phosphoric acid (Total Etch; Ivoclar Vivadent, Schaan, Liechtenstein) for $15 \mathrm{~s}$, followed by thorough rinsing with distilled water. The dentin surfaces were gently dried to remove visible moisture, but desiccation of the dentin was avoided. Using a micro-brush, a universal adhesive (i.e., Tetric N Bond Universal; Ivoclar Vivadent, Schaan, Liechtenstein) was then applied and rubbed onto the dentin surfaces for $20 \mathrm{~s}$, air-dried until the adhesive solution showed no visible motion, and then light-cured for $20 \mathrm{~s}$. The molars were randomly distributed between two groups $(n=5)$. Group I was restored with alkasite restorative material $\mathrm{CN}$ (Ivoclar Vivadent, Schaan, Liechtenstein) and Group II with a light-cured flowable BF-RBC (i.e., Tetric N-Flow Bulk Fill; Ivoclar Vivadent, Schaan, Liechtenstein). Each restorative material was used according to the manufacturer's instructions and applied in one layer (approximately $4 \mathrm{~mm}$ ) to the dentin surfaces using a silicone mold ( $6 \mathrm{~mm}$ in diameter and $4 \mathrm{~mm}$ in height) to form restorative build-ups. Then, each was light-cured for $40 \mathrm{~s}$ using a light-curing unit (Bluephase ${ }^{\circledR}$, Ivoclar Vivadent, Schaan, Liechtenstein) at a light intensity of $900 \mathrm{~mW} / \mathrm{cm}^{2}$ as verified by a hand-held radiometer. The restorative build-ups were then light-cured for an additional $20 \mathrm{~s}$ after removal of the silicone mold. The bonded samples were stored in distilled water for $24 \mathrm{~h}$ at $37^{\circ} \mathrm{C}$, and then subjected to 5000 thermocycles in distilled water using a thermocycling machine (THE-1100, SD Mechatronik GmbH, Feldkirchen-Westerham, Germany). Each cycle consisted of a 30-s bath at $5{ }^{\circ} \mathrm{C}$ followed by a 5 -s rest, then a 30 -s bath at $55{ }^{\circ} \mathrm{C}$ followed by a 5 -s rest. The bonded samples were then sectioned in the $\mathrm{x}-, \mathrm{y}^{-}$, and $\mathrm{z}$-directions across the adhesive interface into $1 \times 1 \mathrm{~mm}( \pm 0.2 \mathrm{~mm})$ bonded beams (Figure 1). A digital caliber was used to measure the cross-sectional surface area of each bonded beam at the interface, and then each beam was attached to a metal jig and mounted on a universal testing machine. Tensile stress was applied at a cross-speed of $0.5 \mathrm{~mm} / \mathrm{min}$ until failure. The tested beams were fixed onto coded brass stubs and gold sputtered before evaluating the failure modes using a scanning electron microscope (SEM) (JSM-6610LV, JEOL Ltd., Tokyo, Japan) at $20 \mathrm{kV}$ and different magnifications. The failure modes were categorized as follows: adhesive failure at the interface (A); cohesive failure in the restorative material $(\mathrm{CR})$; cohesive failure in the dentin (CD); and mixed failure (M), which refers to a combination of adhesive and cohesive failures.

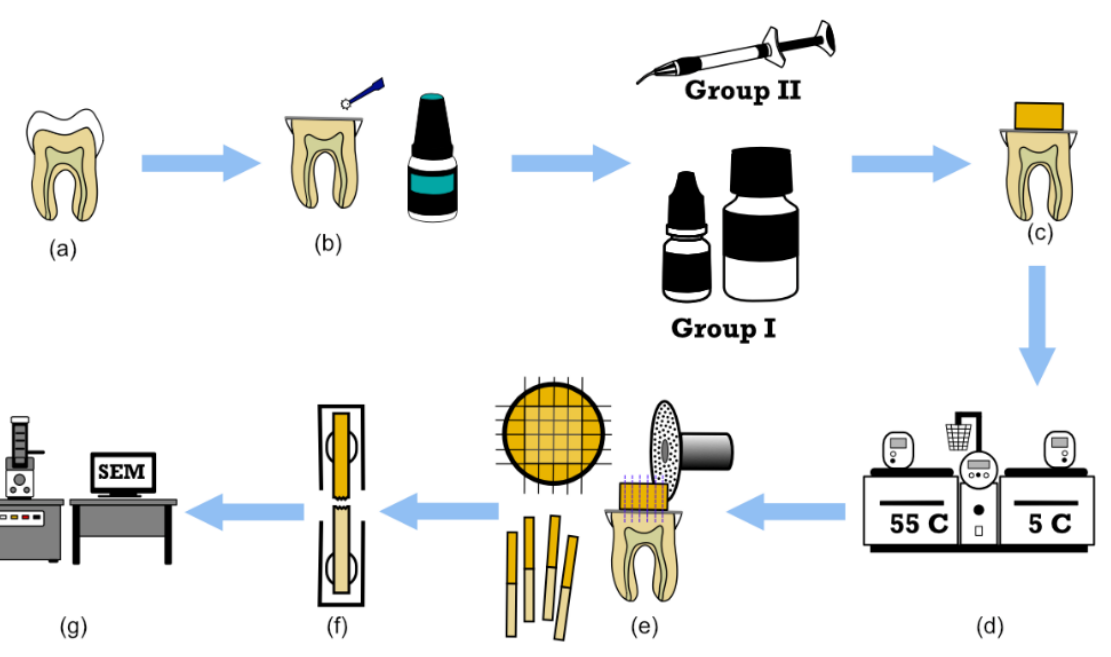

Figure 1. Schematic illustration of micro-tensile bond strength ( $\mu \mathrm{TBS})$. (a) Sound molars, $(\mathbf{b})$ application 
of the adhesive to the mid-coronal dentin, (c) restorative build-up with Cention $\mathrm{N}(\mathrm{CN})$ (group I) or bioactive bulk-fill resin-based composite (BF-RBC) (group II), (d) thermocycling, (e) sectioning of the bonded samples into beams, (f) $\mu$ TBS test, and (g) failure mode assessment.

\subsection{Cytotoxicity and Cell Morphology Analysis}

Two custom-made silicone molds were used to prepare eighteen discs of each material with a diameter of $6 \mathrm{~mm}$. For each material, half of the discs were of $2 \mathrm{~mm}$ thickness $(\mathrm{n}=9)$, while the other half were of $4 \mathrm{~mm}(\mathrm{n}=9)$. For both materials and thicknesses, the RBC discs were built as one layer. The discs were sterilized for $1 \mathrm{~h}$ at each side under an ultra-violet (UV) light before they were placed in the wells with previously cultured human gingival fibroblast cells (HGFCs). HGFCs were cultured in 24-well plates, seeded at $5 \times 104$ cells/well using the basic medium of HGFCs [25]. After $24 \mathrm{~h}$ of incubation, the RBCs discs prepared on the same day and sterilized were placed on the monolayer and incubated at $37^{\circ} \mathrm{C}\left(5 \% \mathrm{CO}_{2}\right)$ for 1,3 , and 7 days. The cellular viability of the HGFCs was evaluated after 1, 3, and 7 days using the AlamarBlue ${ }^{\circledR}$ (Biosource, Camarillo, CA, USA). The active component of AlamarBlue ${ }^{\circledR}$ is resazurin, which is nontoxic, blue in colour, and non-fluorescent. Viable cells reduce resazurin to the fluorescent resorufin, which can be detected by measuring fluorescence at $595 \mathrm{~nm}$. At the required time points (days 1,3, and 7), the medium was removed and fresh HGFCs basic medium containing 10\% (vol/vol) AlamarBlue ${ }^{\circledR}$ was added to each well according to the manufacturer's instructions. After $1 \mathrm{~h}$ of incubation at $37^{\circ} \mathrm{C}$, triplicate, $200 \mu \mathrm{L}$ samples from each well were placed into the individual wells of a 96-well plate and the fluorescence intensity was measured with a fluorescent plate reader (Tecan, Männedorf, Switzerland) using an excitation wavelength of $540 \mathrm{~nm}$ and an emission wavelength of $570 \mathrm{~nm}$. The fluorescence readings of cell-free samples (i.e., the negative controls) were determined to detect any dye changes that occurred in the absence of cells. These negative controls indicated no significant interaction between AlamarBlue ${ }^{\circledR}$ and the two RBCs used. Therefore, fluorescence was corrected using the value of $10 \%$ AlamarBlue ${ }^{\circledR}$ solution in non-cell-seeded medium in presence of the RBC discs as a negative control. The experiments were performed in triplicate and repeated twice. To assess the cells morphological changes of the cells at days 1,3, and 7, a light microscope was used and photographs were taken through a scan microscope using software (Aperio ImageScope, Leica Biosystems Imaging, Inc., Buffalo Grove, IL, USA).

\subsection{Statistical Analysis}

For $\mu$ TBS, averages across all beams from each tooth were used as a statistical unit [26]. Independent t-test was used to analyze the $\mu$ TBS data $(\alpha=0.05)$. One-way and two-way analysis of variance (ANOVA) were utilized to analyze the data for overall significance considering the effect of composite material, thickness, and their interactions on cell viability. Tukey's post-hoc tests were used to compare the difference between the means of specific group's means. GraphPad Prism 7.0 (GraphPad Software, Inc., San Diego, CA, USA) was used for the statistical analyses.

\section{Results}

\section{1. $\mu T B S$}

Thirty beams were tested for each group. There were eight and six pretest failures for groups I and II, respectively, counted as $0 \mathrm{MPa}$. Figure 2 illustrates the means and standard deviations of the $\mu \mathrm{TBS}$ data (in $\mathrm{MPa}$ ) from the two groups. The $\mu \mathrm{TBS}$ of $\mathrm{CN}$ and the BF-RBC were $(42.37 \pm 4.65 \mathrm{MPa})$ and $(47.33 \pm 5.30 \mathrm{MPa})$, respectively, with no statistically significant difference $(p>0.05)$ between them (Figure 2a). Failures were identified as adhesive (A), mixed (M), cohesive failure in the restorative $(\mathrm{CR})$, or cohesive failure in the dentin (CD). In both groups, CR failures were the most predominant, followed by $\mathrm{M}$ failures (Figure 3a,b). The frequencies of the failure modes observed were as follows: 
$\mathrm{A}=20 \%, \mathrm{M}=26.7 \%, \mathrm{CR}=33.3 \%$, and $\mathrm{CD}=20 \%$ for group $\mathrm{I}$, and $\mathrm{A}=20 \%, \mathrm{M}=23.3 \%, \mathrm{CR}=40 \%$, and $\mathrm{CD}=16.7 \%$ for group II (Figure $2 \mathrm{~b}$ ).

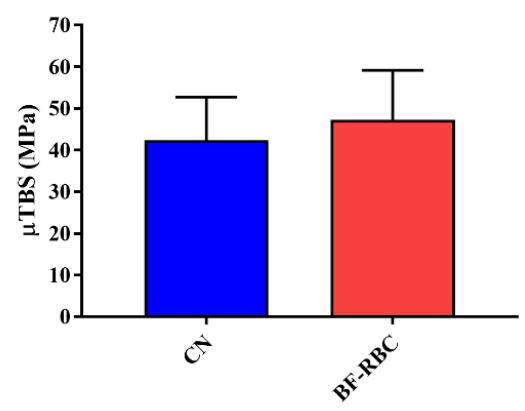

(a)

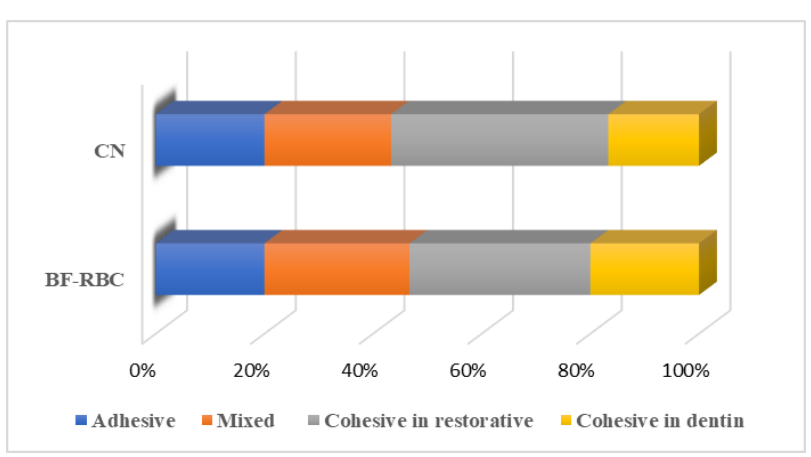

(b)

Figure 2. (a): $\mu \mathrm{TBS}$ for $\mathrm{CN}$ and the BF-RBC (b): Frequencies of failure modes for $\mathrm{CN}$ and the BF-RBC.

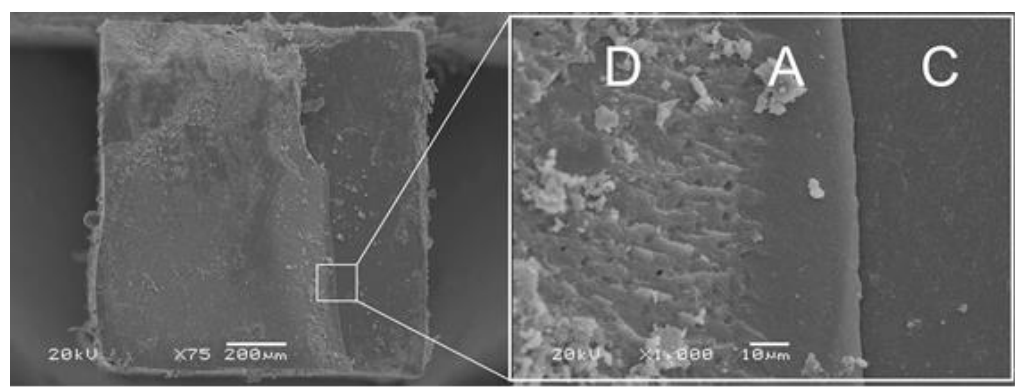

(a)

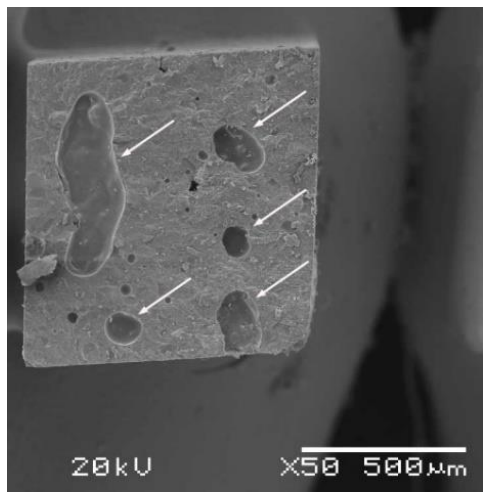

(b)

Figure 3. (a) Scanning electron microscope (SEM) micrographs $(\times 75$ and $\times 1000)$ of mixed failures (D, dentin; A, adhesive; C, resin-based composite (RBC)). (b) SEM micrograph $(\times 50)$ of cohesive failures in the $\mathrm{CN}$ (arrows refer to voids).

\subsection{Cytotoxicity}

For both RBC materials of the two thicknesses, HGFCs remained viable throughout the culture time $(7$ days), with significant increase $(p<0.05)$ in cell viability from days 1 to 3 and from days 3 to 7 (Figure 4a). At day 1, the cell viability for both RBCs of the two thicknesses was significantly lower than the control group (no RBC). The cell viability of the 2-mm-thick BF-RBC was significantly greater $(p<0.05)$ than the 4-mm-thick BF-RBC and CN of both thicknesses, with no statistically significant difference between the 4-mm-thick BF-RBC and the $\mathrm{CN}$ of either thickness (Figure $4 \mathrm{~b}$ ). Interactions between RBC material and thickness had no statistically significant effect $(p>0.05)$ effect on the 
cell viability of either material. At day 3, cell viability for the 2-mm-thick BF-RBC was significantly greater $(p<0.05)$ than $\mathrm{CN}$ of both thicknesses, with no statistically significant difference between the 4-mm-thick BF-RBC and CN or between the 2-mm-thick CN and the 4-mm-thick CN. Moreover, there was no statistically significant difference between the control group (no RBC) and the BF-RBC at either thickness (Figure 4c). Interactions between RBC material and thickness had a statistically significant effect $(p<0.05)$ on the cell viability of both materials. At day 7, the cell viability for both RBCs of 2 or $4 \mathrm{~mm}$ thickness was significantly lower than that of the control group (no RBC). The cell viability of the 2-mm-thick BF-RBC was significantly greater $(p<0.05)$ than that of the 4-mm-thick CN, with no statistically significant difference between the 2-mm-thick BF-RBC and the 4-mm-thick BF-RBC or between the 2-mm-thick CN and 4-mm-thick CN (Figure 4d). Moreover, there was no statistically significant difference between either RBCs at a thickness of $4 \mathrm{~mm}$. Interactions between RBC material and thickness had no statistically significant effect $(p>0.05)$ on the cell viability of either material.

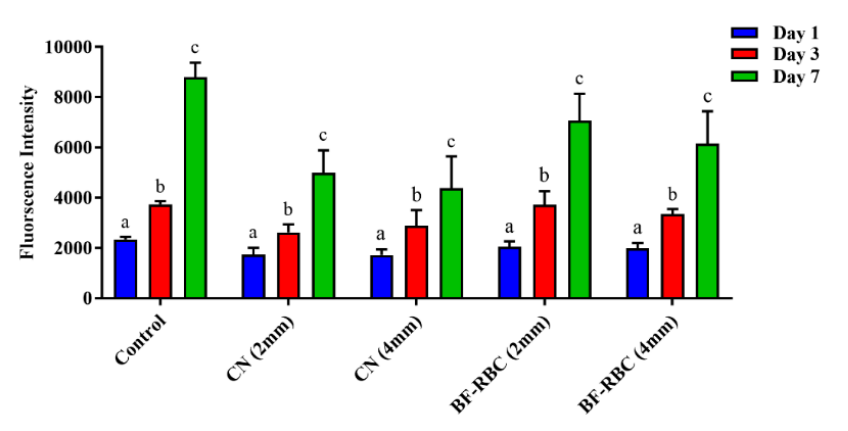

(a)

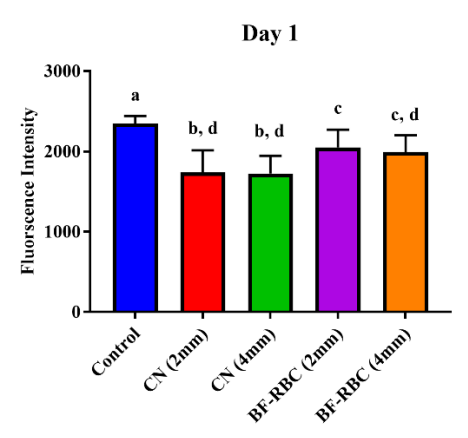

(b)

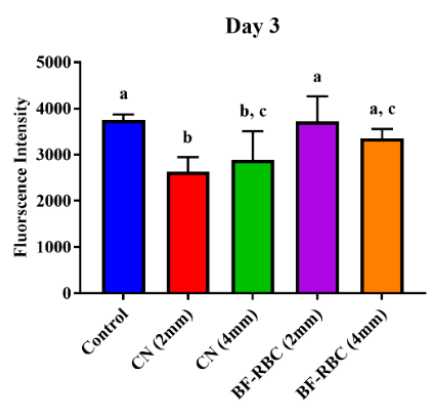

(c)

Day 7

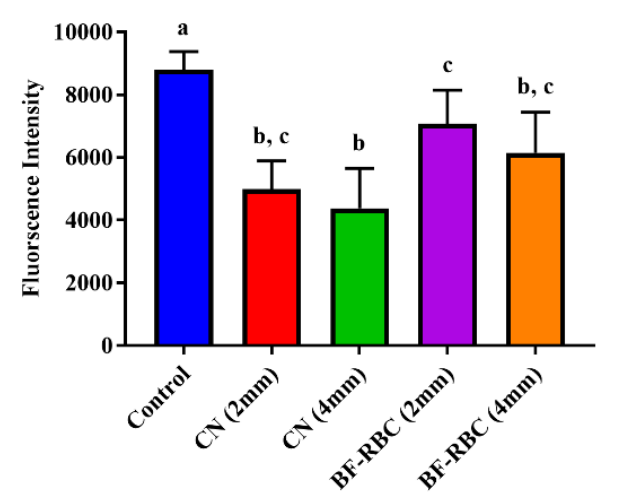

(d)

Figure 4. Effect of RBCs on the proliferation and activity of human gingival fibroblast cells (HGFCs). 
(a) Effect of time on HGFC proliferation for different groups; different letters indicate statistically significant differences within each group. (b-d) The effect of RBCs on the proliferation and activity of HGFCs at days 1, 3, and 7, respectively; different letters indicate statistically significant differences between groups.

\subsection{Cell Morphology Analysis}

The morphological changes in the HGFCs for different groups are presented in Figure 5. HGFCs (control) were spindle-shaped in appearance with extended cellular processes, filopodia, and lamellipodia. Varying degrees of morphologic alterations were observed for the various RBC discs. At day 1, HGFCs grown with 2- and 4-mm-thick CN were small, retracted, and rounded, with condensed and fragmented nuclei morphology, while less marked changes were observed for the 2- and 4-mm-thick BF-RBC groups. At days 3 and 7, the cells regained their original spindle shape. For all groups, the density of the HGFCs increased at days 3 and 7.

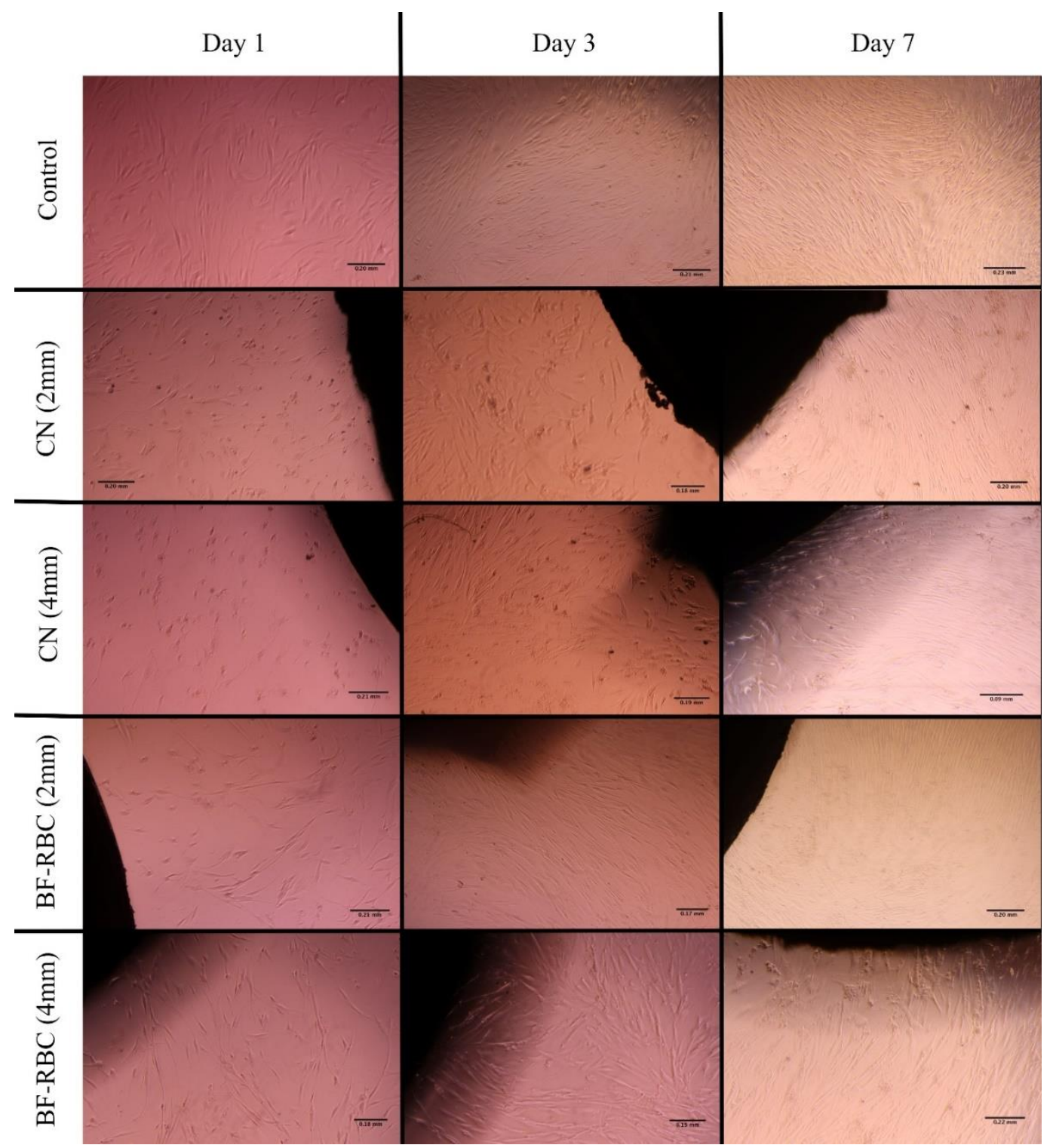

Figure 5. Microscopic images showing the morphological changes of the HGFCs for the different groups at days 1,3 , and 7 . 


\section{Discussion}

This study was designed to evaluate the resin-dentin $\mu \mathrm{TBS}$ and cytotoxicity of $\mathrm{CN}$ compared to a flowable BF-RBC, given that this type of BF-RBC could provide superior curing compared to BF-RBCs of regular viscosity [11]. The curing of BF-RBCs might have a material-dependent effect on resin-dentin $\mu$ TBS [27], and could affect their cytotoxicity [28]. Despite its technique sensitivity, the $\mu$ TBS test was applied in this study because it is a versatile and effective method for evaluating the resin-dentin bond strength [29-31]. Compared to SBS tests, $\mu$ TBS data may correlate better with clinical outcomes of RBC restorations [32]. Bonded samples were subjected to thermocycling to simulate intra-oral thermal conditions [33]. To focus on the impact of the restorative material on the resin-dentin bond strength, a single adhesive was used with both CN and the flowable BF-RBC. The $\mu$ TBS results showed no statistically significant difference between $\mathrm{CN}$ and the BF-RBC. Therefore, the first hypothesis was confirmed. Several all-in-one adhesives reportedly have chemical incompatibilities with dualor self-cured RBCs $[34,35]$. The primary cause could be the residual acidic monomers in universal (self-etch) adhesives of less than $\mathrm{pH} 3$, whereby the polymerization of dual- or self-cured RBCs can be inhibited [35-38], decreasing the bond strength. For this reason, some manufacturers provide a self-curing activator for their universal (self-etch) adhesives. Despite the positive effects of these activators, their influence might be material dependent [39]. Although the adhesive used in this study was of $\mathrm{pH}(2.5-3)$, the bond strength was not affected. This could be attributed to the chemical compatibility between this adhesive and the $\mathrm{CN}$, and to the efficacy of the $\mathrm{CN}$ polymerization system. The liquid component of $\mathrm{CN}$ contains two Norrish type 1 photo-initiators (i.e., a dibenzoyl germanium derivative and an acyl phosphine oxide), which might be more reactive than camphorquinone, the most widely used photo-initiator in restorative materials [40]. Additional light-curing can accelerate the polymerization kinetics of $\mathrm{CN}$ [12] and can improve $\mathrm{CN}$ mechanical properties, such as wear resistance [41]. Another factor that might affected the bond strength of $\mathrm{CN}$ is its high mechanical properties, which might be similar to those of RBCs of regular viscosity [12]. This can be explained by the filler content of $\mathrm{CN}$, which accounts for $78.4 \%$ of the product by weight. The filler content is directly related to the mechanical properties of RBC materials [42]. The most predominant failure modes in both groups were $\mathrm{CR}$ and $\mathrm{M}$ failures. This can be explained by the high stress levels in the dentin and the RBC materials [43] in addition to the relatively high bond strengths obtained in both groups. Aging by thermocycling can influence the resin-dentin bond strength [44] because of stresses created as a result of contraction and expansion [45]. Eliason and Dahl recently found that thermal changes in samples can be significantly influenced by the size of the samples and by dwell time during thermocycling [46]. They also found that dwell times of 20 to $30 \mathrm{~s}$, applied in many thermocycling protocols, could be insufficient for large size samples [46] such as the bonded samples in this study. Samples thermocycling using a short dwell time before sectioning likely limits the effect of thermal changes on the bonded interface, and the mechanical properties of the restorative materials. Accordingly, the frequencies of $\mathrm{CR}$ and $\mathrm{M}$ failures in restorative materials might be explained by the $\mu$ TBS achieved, which might not have been negatively affected by the thermocycling protocol applied in this study. Moreover, hand-mixing could be associated with the presence of voids within the restorative materials, which might be a cause of cohesive failure in restorative materials. This could be supported by the presence of voids, detected during our failure mode assessment (Figure 3b).

Despite their limitations, the advantages of in-vitro cytotoxicity tests include the control of the environmental conditions of cells, and the precise measurement of the response of the cells to restorative materials [21]. The biological effect of restorative materials can be evaluated by several methods [21]; for example, cell viability tests can be used to evaluate cytotoxicity of materials [47]. In such tests, certain cell lines should be used to mimic the clinical conditions [48]. HGFCs can be exposed to resin monomers released from $\mathrm{RBC}$ restorations [49,50]; thus, this cell line was used in this study. To evaluate the cytotoxic effect of material thickness, both materials were tested at 2 and $4 \mathrm{~mm}$. RBC discs were sterilized or decontaminated with an UV-light, despite its possible adverse effects on mechanical and biological properties of RBC materials [51]. Cell viability was assessed using the AlamarBlue ${ }^{\circledR}$ test, 
as fluorescence intensity could be related to the number and activity of cells [25]. The cell viability results showed that cells were viable, with constant growing over the seven-day period, which indicates that both materials are biocompatible at thicknesses of 2 and $4 \mathrm{~mm}$. However, the cell viability for the 2- and 4-mm-thick CN was significantly lower than that of the 2-mm-thick BF-RBC at days 1 and 3. Moreover, at day 1 , more prominent cell morphological changes were noted for $\mathrm{CN}$ groups. Therefore, the second hypothesis was partially rejected. The higher cell viability for the 2-mm-thick BF-RBC may be explained by the improved degree of conversion and the depth of cure at this thickness due to better penetration of the curing light.

One of the basic characteristics of $\mathrm{CN}$ is its ion releasing property due to presence of alkaline fillers. CN releases fluoride amounts comparable to those of RMGIC [18]. This can, in part, explain the difference between the two materials. The cytotoxic effect of fluoride-releasing materials can be correlated to the concentration of fluoride ions released [52], as they can induce inflammation and apoptosis of HGFCs [53]. The degree of conversion of $\mathrm{CN}$ could be comparable to that of conventional RBCs [18]. Cytotoxicity of BF-RBCs can be affected by the depth of cure [28], and the BF-RBCs show variable degree of conversion rates and depth of cure at different thicknesses $[5,54]$. Dual-cure RBCs may have less cytotoxic effects based on monomer release [55], as they combine various initiation systems that enhance the degree of conversion [56]. It is noteworthy that the difference between the cell viability of the 2- and 4-mm-thick $\mathrm{CN}$ was statistically insignificant over seven-day period. This can be attributed to their similar polymerization kinetics at the two thicknesses [12]. In addition, this might be also attributed to the similar levels of ion release at both thicknesses; however, further investigations should be performed to confirm this speculation.

The thermocycling protocol, short-term aging, and the use of one BF-RBC for comparison with $\mathrm{CN}$ are of the limitations of this study. Further long-term studies using different universal adhesives and self-curing activators to compare $\mathrm{CN}$ to dual-cure $\mathrm{RBC}$ s or hybrid restorative material of regular viscosity are suggested. Moreover, although HGFCs primary cells were used in this study; they were used in a two-dimensional culture system, which might have affected their behavior.

\section{Conclusions}

Given the limitations of this study, $\mathrm{CN}$ provided a resin-dentin micro-tensile bond strength $(\mu \mathrm{TBS})$ that was comparable to that provided by a flowable BF-RBC. Voids within CN might result in cohesive failure in the material during $\mu$ TBS testing. The BF-RBC and $\mathrm{CN}$ showed acceptable cytotoxicity over 7-day period, at 2 and $4 \mathrm{~mm}$ thickness. Additionally, $\mathrm{CN}$ showed similar cytotoxic effects on HGFCs at 2 and $4 \mathrm{~mm}$.

Author Contributions: Conceptualization, M.M.A. and A.A.; methodology, T.A., A.M.A., M.M.A., and D.A.; software, F.A.; validation, A.A., M.M.A., and D.A.; formal analysis, M.M.A., D.O.; investigation, T.A., A.M.A., and M.M.A.; resources, M.M.A., D.A., and A.A.; data curation, F.A., D.A.; writing-original draft preparation, M.M.A., D.A., and N.M.M.; writing-review and editing, M.M.A., N.M.M.; visualization, A.A.; supervision, A.A., N.M.M.; project administration, M.M.A., A.A. All authors have read and agreed to the published version of the manuscript.

Funding: The authors are grateful to the Deanship of Scientific Research, King Saud University for funding this study through the Vice Deanship of Scientific Research Chairs and Research Chair for Dental and Oral Rehabilitation, Engineer Abdullah Bugshan.

Acknowledgments: The authors are grateful to the Deanship of Scientific Research, King Saud University for funding this study through the Vice Deanship of Scientific Research Chairs and Research Chair for Dental and Oral Rehabilitation, Engineer Abdullah Bugshan. The authors are grateful to Ivoclar Vivadent for their support providing Cention $\mathrm{N}$ restorative material.

Conflicts of Interest: The authors declare no conflict of interest. 


\section{References}

1. Deliperi, S.; Bardwell, D.N. Multiple cuspal-coverage direct composite restorations: Functional and esthetic guidelines. J. Esthet. Restor. Dent. 2008, 20, 300-312. [CrossRef] [PubMed]

2. Lynch, C.D.; Opdam, N.J.; Hickel, R.; Brunton, P.A.; Gurgan, S.; Kakaboura, A.; Shearer, A.C.; Vanherle, G.; Wilson, N.H. Guidance on posterior resin composites: Academy of Operative Dentistry-European Section. J. Dent. 2014, 42, 377-383. [CrossRef] [PubMed]

3. Ferracane, J.L. Resin composite-State of the art. Dent. Mater. 2011, 27, 29-38. [CrossRef] [PubMed]

4. Chesterman, J.; Jowett, A.; Gallacher, A.; Nixon, P. Bulk-fill resin-based composite restorative materials: A review. Br. Dent. J. 2017, 222, 337-344. [CrossRef] [PubMed]

5. Lima, R.B.W.; Troconis, C.C.M.; Moreno, M.B.P.; Murillo-Gomez, F.; De Goes, M.F. Depth of cure of bulk fill resin composites: A systematic review. J. Esthet. Restor. Dent. 2018, 30, 492-501. [CrossRef] [PubMed]

6. Toh, W.S.; Yap, A.U.; Lim, S.Y. In Vitro Biocompatibility of Contemporary Bulk-fill Composites. Oper. Dent. 2015, 40, 644-652. [CrossRef] [PubMed]

7. Gerula-Szymanska, A.; Kaczor, K.; Lewusz-Butkiewicz, K.; Nowicka, A. Marginal integrity of flowable and packable bulk fill materials used for class II restorations-A systematic review and meta-analysis of in vitro studies. Dent. Mater. J. 2020, 35, 335-344. [CrossRef] [PubMed]

8. Cidreira Boaro, L.C.; Pereira Lopes, D.; de Souza, A.S.C.; Lie Nakano, E.; Ayala Perez, M.D.; Pfeifer, C.S.; Goncalves, F. Clinical performance and chemical-physical properties of bulk fill composites resin-A systematic review and meta-analysis. Dent. Mater. 2019, 35, e249-e264. [CrossRef]

9. Veloso, S.R.M.; Lemos, C.A.A.; de Moraes, S.L.D.; do Egito Vasconcelos, B.C.; Pellizzer, E.P.; de Melo Monteiro, G.Q. Clinical performance of bulk-fill and conventional resin composite restorations in posterior teeth: A systematic review and meta-analysis. Clin. Oral Investig. 2019, 23, 221-233. [CrossRef]

10. Bellinaso, M.D.; Soares, F.Z.M.; Rocha, R.O. Do bulk-fill resins decrease the restorative time in posterior teeth? A systematic review and meta-analysis of in vitro studies. J. Investig. Clin. Dent. 2019, 10, e12463. [CrossRef]

11. Reis, A.F.; Vestphal, M.; Amaral, R.C.D.; Rodrigues, J.A.; Roulet, J.F.; Roscoe, M.G. Efficiency of polymerization of bulk-fill composite resins: A systematic review. Braz. Oral. Res. 2017, 31, 37-48. [CrossRef] [PubMed]

12. Ilie, N. Comparative Effect of Self- or Dual-Curing on Polymerization Kinetics and Mechanical Properties in a Novel, Dental-Resin-Based Composite with Alkaline Filler. Materials 2018, 11, 108. [CrossRef] [PubMed]

13. Ak, A.T.; Alpoz, A.R.; Bayraktar, O.; Ertugrul, F. Monomer Release from Resin Based Dental Materials Cured with LED and Halogen Lights. Eur. J. Dent. 2010, 4, 34-40. [CrossRef] [PubMed]

14. Sigusch, B.W.; Pflaum, T.; Völpel, A.; Gretsch, K.; Hoy, S.; Watts, D.C.; Jandt, K.D. Resin-composite cytotoxicity varies with shade and irradiance. Dent. Mater. 2012, 28, 312-319. [CrossRef] [PubMed]

15. Salehi, S.; Gwinner, F.; Mitchell, J.C.; Pfeifer, C.; Ferracane, J.L. Cytotoxicity of resin composites containing bioactive glass fillers. Dent. Mater. 2015, 31, 195-203. [CrossRef] [PubMed]

16. Ebrahimi Chaharom, M.E.; Bahari, M.; Safyari, L.; Safarvand, H.; Shafaei, H.; Jafari Navimipour, E.; Alizadeh Oskoee, P.; Ajami, A.A.; Abed Kahnamouei, M. Effect of preheating on the cytotoxicity of bulk-fill composite resins. J. Dent. Res. Dent. Clin. Dent. Prospect. 2020, 14, 19-25. [CrossRef]

17. Roulet, J.; Hussein, H.; Abdulhameed, N.; Shen, C. In vitro wear of two bioactive composites and a glass ionomer cement. Dtsch. Zahnärztl. Z. Int. 2019, 1, 24-30.

18. Panpisut, P.; Toneluck, A. Monomer conversion, dimensional stability, biaxial flexural strength, and fluoride release of resin-based restorative material containing alkaline fillers. Dent. Mater. J. 2020, 39, 608-615. [CrossRef]

19. Donly, K.J.; Liu, J.A. Dentin and enamel demineralization inhibition at restoration margins of Vitremer, Z 100 and Cention, N. Am. J. Dent. 2018, 31, 166-168.

20. Roulet, J.F. Is in vitro research in restorative dentistry useless? J. Adhes. Dent. 2012, 14, 103-104.

21. Wataha, J.C. Predicting clinical biological responses to dental materials. Dent. Mater. 2012, $28,23-40$. [CrossRef] [PubMed]

22. Armstrong, S.; Geraldeli, S.; Maia, R.; Raposo, L.H.; Soares, C.J.; Yamagawa, J. Adhesion to tooth structure: A critical review of "micro" bond strength test methods. Dent. Mater. 2010, 26, e50-e62. [CrossRef] [PubMed]

23. Naz, F.; Samad Khan, A.; Kader, M.A.; Al Gelban, L.O.S.; Mousa, N.M.A.; Asiri, R.S.H.; Hakeem, A.S. Comparative evaluation of mechanical and physical properties of a new bulk-fill alkasite with conventional restorative materials. Saudi Dent. J. 2020, in press. 
24. Yao, C.; Ahmed, M.H.; Zhang, F.; Mercelis, B.; Van Landuyt, K.L.; Huang, C.; Van Meerbeek, B. Structural/Chemical Characterization and Bond Strength of a New Self-Adhesive Bulk-fill Restorative. J. Adhes. Dent. 2020, 22, 85-97. [PubMed]

25. Nakayama, G.; Caton, M.; Nova, M.; Parandoosh, Z. Assessment of the Alamar Blue assay for cellular growth and viability in vitro. J. Immunol. Method. 1997, 204, 205. [CrossRef]

26. Eckert, G.J.; Platt, J.A. A statistical evaluation of microtensile bond strength methodology for dental adhesives. Dent. Mater. 2007, 23, 385-391. [CrossRef]

27. Makhdoom, S.N.; Campbell, K.M.; Carvalho, R.M.; Manso, A.P. Effects of curing modes on depth of cure and microtensile bond strength of bulk fill composites to dentin. J. Appl. Oral. Sci. 2020, 28, e20190753. [CrossRef]

28. Lee, S.M.; Kim, S.Y.; Kim, J.H.; Jun, S.K.; Kim, H.W.; Lee, J.H.; Lee, H.H. Depth-Dependent Cellular Response from Dental Bulk-Fill Resins in Human Dental Pulp Stem Cells. Stem. Cells Int. 2019, 2019, 1251536. [CrossRef]

29. Pashley, D.H.; Carvalho, R.M.; Sano, H.; Nakajima, M.; Yoshiyama, M.; Shono, Y.; Fernandes, C.A.; Tay, F. The microtensile bond test: A review. J. Adhes. Dent. 1999, 1, 299-309.

30. Sano, H.; Chowdhury, A.F.M.A.; Saikaew, P.; Matsumoto, M.; Hoshika, S.; Yamauti, M. The microtensile bond strength test: Its historical background and application to bond testing. Jpn. Dent. Sci. Rev. 2020, 56, 24-31. [CrossRef]

31. Van Meerbeek, B.; Peumans, M.; Poitevin, A.; Mine, A.; Van Ende, A.; Neves, A.; De Munck, J. Relationship between bond-strength tests and clinical outcomes. Dent. Mater. 2010, 26, e100-e121. [CrossRef]

32. Heintze, S.D.; Rousson, V.; Mahn, E. Bond strength tests of dental adhesive systems and their correlation with clinical results-A meta-analysis. Dent. Mater. 2015, 31, 423-434. [CrossRef] [PubMed]

33. Gale, M.S.; Darvell, B.W. Thermal cycling procedures for laboratory testing of dental restorations. J. Dent. 1999, 27, 89-99. [CrossRef]

34. Sunada, N.; Ishii, R.; Shiratsuchi, K.; Shimizu, Y.; Tsubota, K.; Kurokawa, H.; Miyazaki, M. Ultrasonic measurement of the effects of adhesive application and power density on the polymerization behavior of core build-up resins. Acta Odontol. Scand. 2013, 71, 137-143. [CrossRef] [PubMed]

35. Sanares, A.M.E.; Itthagarun, A.; King, N.M.; Tay, F.R.; Pashley, D.H. Adverse surface interactions between one-bottle light-cured adhesives and chemical-cured composites. Dent. Mater. 2001, 17, 542-556. [CrossRef]

36. Tay, F.R.; Suh, B.I.; Pashley, D.H.; Prati, C.; Chuang, S.F.; Li, F. Factors contributing to the incompatibility between simplified-step adhesives and self-cured or dual-cured composites. Part II. Single-bottle, total-etch adhesive. J. Adhes. Dent. 2003, 5, 91-105.

37. Suh, B.I.; Feng, L.; Pashley, D.H.; Tay, F.R. Factors contributing to the incompatibility between simplified-step adhesives and chemically-cured or dual-cured composites. Part III. Effect of acidic resin monomers. J. Adhes. Dent. 2003, 5, 267-282.

38. Endo, T.; Finger, W.J.; Hoffmann, M.; Kanehira, M.; Komatsu, M. The role of oxygen inhibition of a self-etch adhesive on self-cure resin composite bonding. Am. J. Dent. 2007, 20, 157-160.

39. Gutierrez, M.F.; Sutil, E.; Malaquias, P.; de Paris Matos, T.; de Souza, L.M.; Reis, A.; Perdigao, J.; Loguercio, A.D. Effect of self-curing activators and curing protocols on adhesive properties of universal adhesives bonded to dual-cured composites. Dent. Mater. 2017, 33, 775-787. [CrossRef]

40. Moszner, N.; Fischer, U.K.; Ganster, B.; Liska, R.; Rheinberger, V. Benzoyl germanium derivatives as novel visible light photoinitiators for dental materials. Dent. Mater. 2008, 24, 901-907. [CrossRef]

41. Roulet, J.F.; Gummadi, S.; Hussein, H.S.; Abdulhameed, N.; Shen, C. In vitro wear of dual-cured bulkfill composites and flowable bulkfill composites. J. Esthet. Restor. Dent. 2020, 32, 512-520. [CrossRef]

42. Ilie, N.; Hickel, R. Investigations on mechanical behaviour of dental composites. Clin. Oral. Investig. 2009, 13, 427-438. [CrossRef] [PubMed]

43. Soderholm, K.J.; Geraldeli, S.; Shen, C. What do microtensile bond strength values of adhesives mean? J. Adhes. Dent. 2012, 14, 307-314. [PubMed]

44. Amaral, F.L.; Colucci, V.; Palma-Dibb, R.G.; Corona, S.A. Assessment of in vitro methods used to promote adhesive interface degradation: A critical review. J. Esthet. Restor. Dent. 2007, 19, 340-353. [CrossRef] [PubMed] 
45. De Munck, J.; Van Landuyt, K.; Peumans, M.; Poitevin, A.; Lambrechts, P.; Braem, M.; Van Meerbeek, B. A critical review of the durability of adhesion to tooth tissue: Methods and results. J. Dent. Res. 2005, 84, 118-132. [CrossRef] [PubMed]

46. Eliasson, S.T.; Dahl, J.E. Effect of thermal cycling on temperature changes and bond strength in different test specimens. Biomater. Investig. Dent. 2020, 7, 16-24. [CrossRef]

47. Wiegand, C.; Hipler, U.C. Methods for the measurement of cell and tissue compatibility including tissue regeneration processes. GMS Krankenhhyg. Interdiszip. 2008, 3, 1-11.

48. Schmalz, G.; Schuster, U.; Nuetzel, K.; Schweikl, H. An in vitro pulp chamber with three-dimensional cell cultures. J. Endod. 1999, 25, 24-29. [CrossRef]

49. Durner, J.; Wellner, P.; Hickel, R.; Reichl, F.X. Synergistic interaction caused to human gingival fibroblasts from dental monomers. Dent. Mater. 2012, 28, 818-823. [CrossRef]

50. Urcan, E.; Scherthan, H.; Styllou, M.; Haertel, U.; Hickel, R.; Reichl, F.X. Induction of DNA double-strand breaks in primary gingival fibroblasts by exposure to dental resin composites. Biomaterials 2010, 31, $2010-2014$. [CrossRef]

51. Mattioli-Belmonte, M.; Natali, D.; Tosi, G.; Torricelli, P.; Totaro, I.; Zizzi, A.; Fini, M.; Sabbatini, S.; Giavaresi, G.; Biagini, G. Resin-based dentin restorative materials under accelerated ageing: Bio-functional behavior. Int. J. Artif. Organ. 2006, 29, 1000-1011. [CrossRef]

52. Kanjevac, T.; Milovanovic, M.; Volarevic, V.; Lukic, M.L.; Arsenijevic, N.; Markovic, D.; Zdravkovic, N.; Tesic, Z.; Lukic, A. Cytotoxic effects of glass ionomer cements on human dental pulp stem cells correlate with fluoride release. Med. Chem. 2012, 8, 40-45. [CrossRef] [PubMed]

53. Inkielewicz-Stepniak, I.; Santos-Martinez, M.J.; Medina, C.; Radomski, M.W. Pharmacological and toxicological effects of co-exposure of human gingival fibroblasts to silver nanoparticles and sodium fluoride. Int. J. Nanomed. 2014, 9, 1677-1687.

54. Gonçalves, F.; Campos, L.M.P.; Rodrigues-Júnior, E.C.; Costa, F.V.; Marques, P.A.; Francci, C.E.; Braga, R.R.; Boaro, L.C.C. A comparative study of bulk-fill composites: Degree of conversion, post-gel shrinkage and cytotoxicity. Braz. Oral. Res. 2018, 32, e17. [CrossRef] [PubMed]

55. Franz, A.; Spinell, T.; Graf, A.; Wutzel, H.; Liska, R.; Watts, D.C.; Moritz, A.; Schedle, A. Cytotoxicity of post and core composites as a function of environmental conditions. Dent. Mater. 2014, 30, 1179-1186. [CrossRef] [PubMed]

56. Kwon, T.Y.; Bagheri, R.; Kim, Y.K.; Kim, K.H.; Burrow, M.F. Cure mechanisms in materials for use in esthetic dentistry. J. Investig. Clin. Dent. 2012, 3, 3-16. [CrossRef] [PubMed] 